\title{
Knowledge Sharing Behaviour and Human Resource Management
}

\author{
Muhammad Tariq \\ Department of Computer Science, Minhaj University Lahore, Punjab, Pakistan \\ Muahmmad Farooq \\ Department of Administrative Sciences, University of Punjab Lahore, Punjab, Pakistan
}

\begin{abstract}
In the era of the knowledge-based and more attention to the knowledge of the management of matter investigators to understanding .Knowledge sharing behavior has been predictable as an significant factor for knowledge management. However, few studies have explored the behavior of sharing public sector knowledge. The latest Federal Viewpoint The survey data used in this study investigates the relationship between human resources (HR) practices and knowledge sharing behaviors in the public sector, including the role of moderating confidence in the general supervisor. Its believe that their confidence in supervisory practices and HR role-playing Sacred in promoting knowledge sharing behaviors. The results show that the confidence in the moderate supervisor the infliction of HR practices share the relationships between knowledge and behavior. Knowledge sharing can define employees' conversations, cultural exchange of information, until now the learning of skills or the whole free. Sharing occurs for knowledge the organizational and individual level. The details are inexpensive, knowledge sharing is talking to his colleagues help them get something done better, faster and more efficiently. The order of knowing it has no apprehend, organization, re-use them here and there, transferring it to the use of knowledge, according to which is located in the extremity
\end{abstract}

Keywords: HRM Applications, Knowledge Sharing, Knowledge Management (KM), Human Behavior

DOI: $10.7176 / \mathrm{IKM} / 9-10-03$

Publication date: November $30^{\text {th }} 2019$

\section{INTRODUCTION}

Research adds scholastic writing through portraying causal connections dependent on Employees' observations in regards to HRM application and employee knowledge sharing inside organizations. It gives a comprehension of the systems through which HRM application impact the knowledge ability of people and organization. Human resource management and Knowledge sharing both play an important role in any organization and both are necessary to improve for best results. For this purpose main factor is to examine the behavior of employees shall be examined and understand the situation of employees in any organization. Human resources (HR) practices and knowledge sharing behaviors in the public sector, including the role of moderating confidence in the general supervisor. Its believe that their confidence in supervisory practices and HR role-playing Sacred in promoting knowledge sharing behaviors. In this requirements of any employees will be examined. This examination links three hypothetical field; human resource management, knowledge management and knowledge capability shown in Figure.

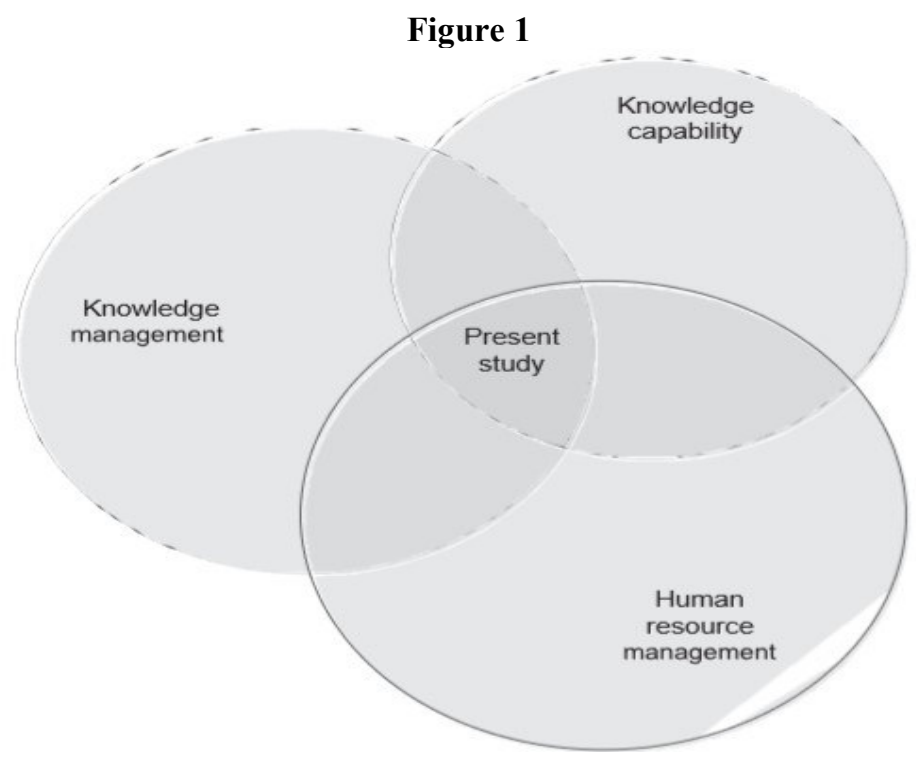


In organizational level knowledge capability deals with workers' information through their joint effort and knowledge distribution (Smith, Collins and Clark, 2005).

Capability of knowledge at a hierarchical dimension additionally connected with workers' earlier learning and experience (Cohen and Levinthal, 1990).

Knowledge is an asset which is presently substituting tangible resources for creation of value in the market place. To get upper hand in organizations, the basic thing is the Capacity of making, trading and applying new knowledge (Kogut and Zander, 1992; Nonaka and Takeuchi, 1995). While beginning of awareness returns to soonest human advancements, it's just thirty years back that the managers and administrators of organizations are perceiving its expanding significance because of creating aggressive markets (Wiig, 1997). The explanations behind this could be because of globalization, quick market development and the learning economy. Information as an asset has a significant job where work is for the most part intelligent in organization which is called knowledge intensive organization.

Because of expanding rivalry in market place, organizations are currently concentrating on the best way to deal with their employee information, as they do with different resources which are utilized for delivering their items and facilities. Knowledge management (KM) has picked up the consideration, through which organizations are starting to put resources into KM activities to improve hierarchical capacity. This thought has been upheld by a few researchers.

HRM impacts creation of knowledge, its achievement and exchange through featuring the connection among HRM and KM (Jerez-Gamez, esCasped-Lorente, and Valle-Cabrera, 2005). For knowledge, HRM applications have increased the look and investigation beforehand which was inaccessible inside organization's knowledge base (Toulson, and Tweed, 2011). HRM applications encourage workers' inspiration as well as duty and develop employee execution the degree which they create fundamental aptitudes which are hard to supplant (Huselid, 1995). Explicit HRM application through knowledge distribution drills draw in employees every day and long term decision making by constructing an atmosphere based on cooperation.

\section{LITERATURE REVIEW}

Organizational reliance on bureaucratic power over assets to acquire prevalent execution has moved from tangible assets to information and abilities (Thite, 2004). Explanations behind that shift is expected to perceiving the information as data as well as an asset with resource value which can assist organizations with functioning all the more successfully (Davenport and Prusak, 1998; Sveiby, 1997).

Workers knowledge (implicit information) being a basic asset can likewise improve hierarchical knowledge and development capacity over knowledge distribution activity (Aulawi, et al., 2008; Cavusgil, Calantone, and Zhao, 2003; Goffin and Koners, 2011; Shamsie and Mannor, 2013).

Knowledge lives both at worker level and at organizational level (De Long and Fahey, 2000). In an observational investigation recommend which despite fact that employees speak to the essential level as far as wherever knowledge exists in organization, distribution of information among workers is basic to exchange, circulate and additional making of more information. (Han, Chiang, and Chang (2010).

Very nearly three decades prior, a few organizations changed their management practices, because of wasteful aspects in conventional managerial practices, so as to fulfill business need. Conventional management practices depended on techniques that needed objectivity, research advancement and logical diligence (Vaughan and Mclean, 1989).

The Management applications changed to people a management application that has reduced the rule that business and employees share typical concern for the working environment with sense of accomplishment and the fulfillment of the organization customer and investors. The job of HRM is basic and fills in as a device that can coordinate information in the working environment to acquire upper hand (Edvardsson, 2008).

As talked about in the past area, HRM is a tool with which to coordinate knowledge in organizations. HRM applications can assist KM activities, for example, employees knowledge sharing. A gathering of HRM practices can encourage workers' cooperation's with different workers to use workers behavior and learning (Cabrera and Cabrera, 2005; Minbaeva 2003).

The significance of HRM in the KM setting has been accentuated in the past areas of this examination proposition. Association's ought not concentrate exclusively on creating KM practices, yet ought to likewise deliberate HRM as a device alongside KM to develop hierarchical capacity (Edvardsson, 2008).

Learning sharing advantages the two people and associations through improved information capacity (Ipe, 2003; Liao, Fei, and Chen, 2007; Lin, 2007)

The main contribution joins explicit HRM applications which encourage the causal connection among workers coordinated effort and knowledge interchange. While past research which has taken an expansive point of view which job of workers joint effort (Tsai and Ghoshal, 1998), our research proposal exhibits that HRM and KM are intertwined and assist one another, yet both of these are rising exploration ideas ( Edvardsson, 2008; Jimenez-Jimenez and Sanz-Valle, 2012; Lam, Tan, Fong, and Ng, 2011). Scientists in the field of business and the 
board propose that majority of knowledge dwells in a person's mind.

\section{RESULT AND DISCUSSION}

Our main purpose to this research is examining the knowledge distribution results and outcome might be noteworthy to support the strategies of government. To comprehend and recognize employees observations regarding effect of HRM applications and knowledge distribution indication on workers' knowledge distribution conduct.

The other objective of our research proposal is to comprehend the results of knowledge sharing in term of as organization and single ability.

Following questions has been planned to obtain our research objectives:

\section{Research Question 1}

Is there a causal connection among explicit HRM applications and knowledge sharing inside organization?

S1: worker recruitment and selection positively affect workers' knowledge sharing behavior.

S2: Rewards and recognition positively affect workers' knowledge sharing behavior.

S3: Employees' coordinated effort as well as their cooperation positively affects workers knowledge sharing behavior.

\section{Research Question 2}

Is there a causal connection among trust and workers' knowledge sharing practices? To address this question, this research proposal has detailed the accompanying hypo investigate proposition to test any causative relationship:

S4: Trust positively affects worker's knowledge sharing conduct.

\section{Research Question 3}

Is there a causative connection among worker knowledge distribution and organizational and single capacity? On respond to the research question, our research proposal figured the accompanying hypothetic proposition to test any causal connections:

S5: workers knowledge sharing positively affects organizational capacity.

S6: workers knowledge sharing positively affects individual capacity

An integrated proposed model is designed in Figure 2.

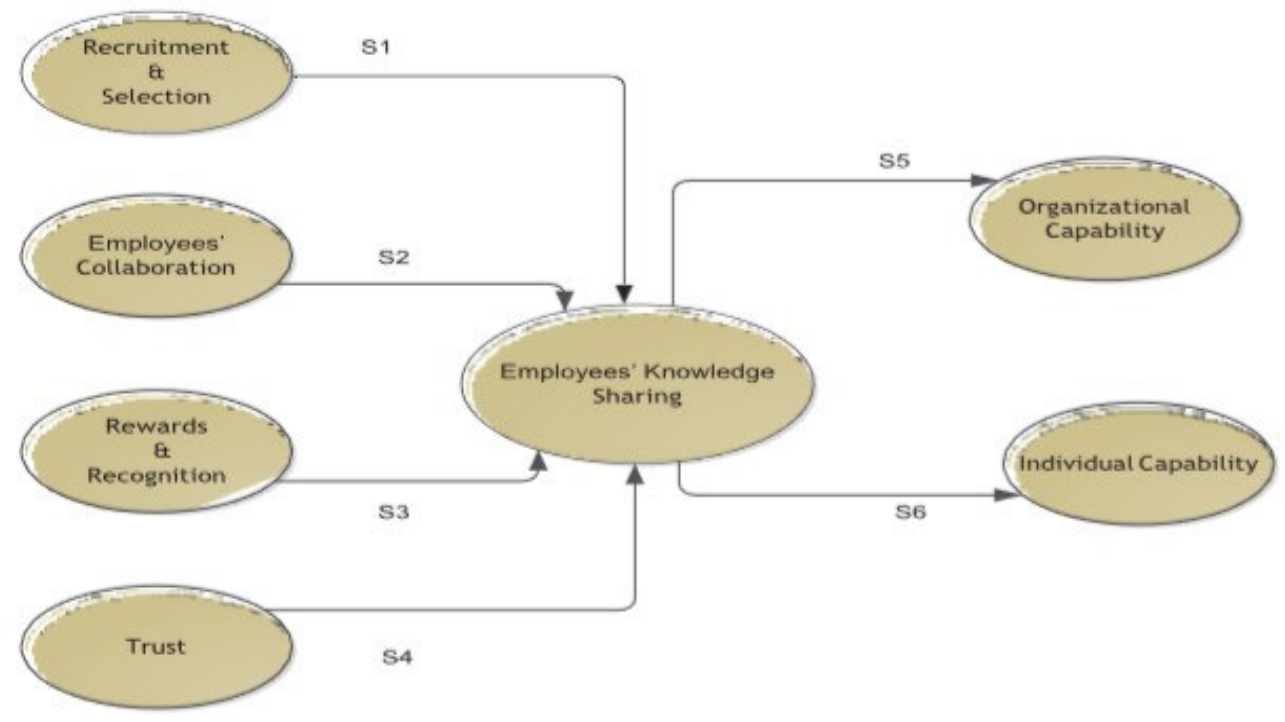

Figure 2. Purposed Model (Integrated)

A survey questionnaire will be used with data collection from Punjab health department to answer the research questions of our research proposal. The overview contained demographical questions, and questions with respect to worker observation about HRM applications, trust, workers' knowledge distribution, organizational capacity and single capacity. Defendants will be approached to answer the queries on the five point Likert scale, running from '1 = Strongly Disagree' to '5 = Strongly Agree', which will be intended quantify the construct of research.

\section{CONCLUSION}

Finally it's conclude about business practices HRM behavior sharing science, competition innovation in performance capacity and firm organization. The empirical results showing HRM practices that are associated with knowledge sharing. Transgression Reward and Training and Development Team Work have a positive impact on the knowledge of employees sharing. HRM is perceived among the works of the master of work, with the payment of the prize and the Team management of human resources and knowledge that they share significantly 
in both areas. Besides, there was ability to share the developer's demonstrated knowledge is closely linked to innovation Unit. I have the same meaning of organization positively in the innovation capacity of the financial and non-financial performance of the company. HRM healthy practices, which can be summarized to encourage employees to share knowledge. The connection of employees in a culture that involves the development of innovation skills during this capacity for innovation is exactly the overall improvement of the company's performance.

\section{References}

1. Smith, K.G., Collins, C.J., Clark, K.D. (2005), Existing knowledge, knowledge creation capability, and the rate of new product introduction in hightechnology firms, Academy of Management Journal, 48(2), 346-357.

2. Cohen, W. M., \& Levinthal, D. A. (1990). Absorptive capacity: A new perspective on learning and innovation. Administrative science quarterly, 35(1), 128-152.

3. Kogut, B., \& Zander, U. (1992). Knowledge of the firm, combinative capabilities, and the replication of technology. Organization science, 3(3), 383-397.

4. Nonaka, I., \& Takeuchi, H. (1995). The knowledge creating company: How Japanese companies create the dynamics of innovation. New York, USA: Oxford University Press.

5. Wiig, K. M. (1997). Knowledge management: an introduction and perspective. Journal of Knowledge Management, 1(1), 6-14.

6. Jerez-Gómez, P., Céspedes - Lorente, J., \& Valle - Cabrera, R. (2005). Organizational learning and compensation strategies: evidence from the Spanish chemical industry. Human Resource Management: Published in Cooperation with the School of Business Administration, The University of Michigan and in alliance with the Society of Human Resources Management, 44(3), 279-299.

7. Jalal, H., Toulson, P., \& Tweed, D. (2011). Exploring employee perceptions of the relationships among knowledge sharing capability, organizational culture and knowledge sharing success: Their implications for HRM practice. In Proceedings of The International Conference On Intellectual Capital, Knowledge Management \& Organizational Learning (pp. 639-646).

8. Huselid, M. A. (1995). The impact of human resource management practices on turnover, productivity, and corporate financial performance. Academy of management journal, 38(3), 635-672.

9. Thite, M. (2004). Strategic positioning of HRM in knowledge-based organizations. Learning Organization, The, 11(1), 28-44.

10. Prusak, L., \& Davenport, T. (1998). Working knowledge: how organizations manage what they know.

11. ERIK SVEIBY, K. A. R. L. (1997). The intangible assets monitor. Journal of Human Resource Costing \& Accounting, 2(1), 73-97.

12. Aulawi, H., Sudirman, I., Suryadi, K., \& Govindaraju, R. (2008, December). Knowledge sharing behavior, antecedent and its influence towards the company's innovation capability. In 2008 IEEE International Conference on Industrial Engineering and Engineering Management (pp. 2092-2096). IEEE.

13. Tamer Cavusgil, S., Calantone, R. J., \& Zhao, Y. (2003). Tacit knowledge transfer and firm innovation capability. Journal of business \& industrial marketing, 18(1), 6-21.

14. Goffin, K., \& Koners, U. (2011). Tacit knowledge, lessons learnt, and new product development. Journal of Product Innovation Management, 28(2), 300-318.

15. Shamsie, J., \& Mannor, M. J. (2013). Looking Inside the dream team: Probing Into the contributions of tacit knowledge as an organizational resource. Organization Science, 24(2), 513-529.

16. De Long, D. W., \& Fahey, L. (2000). Diagnosing cultural barriers to knowledge management. Academy of Management Perspectives, 14(4), 113-127.

17. Han, T. S., Chiang, H. H., \& Chang, A. (2010). Employee participation in decision making, psychological ownership and knowledge sharing: mediating role of organizational commitment in Taiwanese high-tech organizations. The International Journal of Human Resource Management, 21(12), 2218-2233.

18. Vaughan, E., \& McLean, J. (1989). A survey and critique of management selection practices in Australian business firms. Asia Pacific Journal of Human Resources, 27(4), 20-33.

19. Runar Edvardsson, I. (2008). HRM and knowledge management. Employee Relations, 30(5), 553-561.

20. Cabrera, E. F., \& Cabrera, A. (2005). Fostering knowledge sharing through people management practices. The international journal of human resource management, 16(5), 720-735.

21. Minbaeva, D., Pedersen, T., Bjorkman, I., Fey, C., \& Park, H. (2003). MNC Knowledge Transfer, Subsidiary Absorptive Capacity, and HRM. Journal of International Business Studies, 34(6), 586-600.

22. Ipe, M. (2003). Knowledge sharing in organizations: A conceptual framework. Human resource development review, 2(4), 337-359.

23. Liao, S., Fei, W. C., \& Chen, C. C. (2007). Knowledge sharing, absorptive capacity and innovation capability: An empirical study of Taiwan's knowledge intensive industries. Journal of Information Science, 33(3), 340359. 
24. Lin, H. F. (2007). Knowledge sharing and firm innovation capability: An empirical study. International Journal of Manpower, 28(3-4), 315-332.

25. Tsai, \& Ghoshal (1998). Social capital and value creation: The role of intra-firm networks.

Academy of Management Journal, 41, 464-476.

26. Jimenez-Jimenez, D., \& Sanz-Valle, R. (2012). Studying the effect of HRM practices on the knowledge management process. Personnel Review, 42(1), 28-49.

27. Lam, C. H., Tan, P. S. H., Fong, C. Y., Ng, Y. K., \& Ooi, K. B. (2011). The effectiveness of HRM and KM in innovation performance: a literature review and research agenda. International Journal of Innovation and Learning, 9(4), 339-351. 